\title{
Severe paraneoplastic hypoglycemia secondary to a gastrointestinal stromal tumour masquerading as a stroke
}

\author{
G K Dimitriadis ${ }^{1,2,3}$, K Gopalakrishnan5, R Rao', D K Grammatopoulos ${ }^{3,4}$, \\ H S Randeva ${ }^{1,3}$, M O Weickert ${ }^{1}$ and N Murthy ${ }^{1}$
}

${ }^{1}$ Warwick Institute for the Study of Endocrinology, Diabetes and Metabolism (WISDEM Centre), The Arden NET Centre, University Hospitals of Coventry and Warwickshire, UHCW NHS Trust, ENETS CoE, Coventry, UK, ${ }^{2}$ Division of Experimental Medicine, Faculty of Medicine, Imperial College London, Hammersmith Campus, London, UK, ${ }^{3}$ Division of Translational and Systems Medicine, Warwick Medical School, University of Warwick, Coventry, UK, Departments of ${ }^{4} \mathrm{Clinical}$ Biochemistry and ${ }^{5}$ Histopathology, Coventry and Warwickshire Pathology Service, UHCW NHS Trust, Coventry, UK

\author{
Correspondence \\ should be addressed \\ to G K Dimitriadis \\ Email \\ g.dimitriadis@warwick.ac.uk
}

\section{Summary}

We report the case of a 70-year-old previously healthy female who presented acutely to the Accident and Emergency department with left-sided vasomotor symptoms including reduced muscle tone, weakness upon walking and slurred speech. Physical examination confirmed hemiparesis with VIIth nerve palsy and profound hepatomegaly. A random glucose was low at $1.7 \mathrm{mmol} / \mathrm{l}$, which upon correction resolved her symptoms. In hindsight, the patient recalled having had similar episodes periodically over the past 3 months to which she did not give much attention. While hospitalized, she continued having episodes of symptomatic hypoglycaemia during most nights, requiring treatment with i.v. dextrose and/or glucagon. Blood tests including insulin and C-peptide were invariably suppressed, in correlation with low glucose. A Synacthen stimulation test was normal (Cort ( $\left.0^{\prime}\right) 390 \mathrm{nmol} / \mathrm{l}$, Cort $\left.\left(30^{\prime}\right) 773 \mathrm{nmol} / \mathrm{l}\right)$. A computed tomography scan showed multiple lobulated masses in the abdomen, liver and pelvis. An ultrasound guided biopsy of one of the pelvic masses was performed. Immunohistochemistry supported the diagnosis of a gastrointestinal stromal tumour (GIST) positive for CD34 and CD117. A diagnosis of a non islet cell tumour hypoglycaemia (NICTH) secondary to an IGF2 secreting GIST was confirmed with further biochemical investigations (IGF2 $=96.5 \mathrm{nmol} /$; IGF2:IGF1 ratio 18.9 , ULN $<10$ ). Treatment with growth hormone resolved the patient's hypoglycaemic symptoms and subsequent targeted therapy with Imatinib was successful in controlling disease progression over an 8-year observation period.

\section{Learning points:}

- NICTH can be a rare complication of GISTs that may manifest with severe hypoglycaemia and neuroglucopenic symptoms.

- NICTH can masquerade as other pathologies thus causing diagnostic confusion.

- Histological confirmation of GIST induced NICTH and exclusion of other conditions causing hypoglycaemia is essential.

- Mutational analysis of GISTs should be carried out in all cases as it guides treatment decision.

- Tailored management of hypoglycaemia, in this case using growth hormone and targeted cyto-reductive therapy, minimizes the risk of possible life-threatening complications. 


\section{Background}

Gastrointestinal stromal tumours (GISTs) are defined as morphologically spindle cell, epithelioid, or occasionally pleomorphic mesenchymal tumours of the gastrointestinal tract. In Caucasian populations, their annual incidence is $10-15$ cases per million and they are evenly distributed between genders. GIST usually express receptor tyrosine kinase KIT protein and harbour mutation of a gene that encodes for a type III receptor tyrosine kinase (either KIT or platelet-derived growth factor receptor A (PDGFRA)). Approximately $80 \%$ of GISTs harbour KIT and $5 \%$ PDGFRA mutations and $\sim 90 \%$ are CD-117 positive. The ligand for the receptor is a stem-cell factor, which is essential for development and proliferation of a variety of cell types.

GISTs often grow asymptomatically until they are discovered due to the appearance of signs and symptoms related to mass pressure effects, bleeding or bowel perforation. Tumour related hypoglycaemia is rare and most frequently occurs in insulinomas but can also occasionally occur in non-islet cell tumours. Non islet cell tumour hypoglycemia (NICTH) is observed in some epithelial and mesenchymal tumours and rarely also in GISTs.

NICTH is characterised by recurrent fasting hypoglycaemia and associated with the secretion of incompletely processed precursors of insulin-like growth factor (IGF) 2 by the tumour into the circulation. These precursors consist mainly of mature IGF2 with a 21-residue carboxyl extension of the E-domain of pro-IGF2 called pro-IGF2E or 'big'-IGF2 (1).

In this report, we present a rare case of severe NICTH due to overproduction of Insulin Growth Factor 2 (IGF2) secondary to a GIST. The importance of our case is that it raises awareness among healthcare professionals of NICTH as a rare complication of ectopic overproduction of IGF2 in patients with GISTs. This case points out challenges associated with its diagnosis and the importance of symptom control and prompt disease control with either surgery, targeted therapy or combined treatment based on staging.

\section{Case presentation}

In July 2007, a 70-year-old Caucasian retired female presented to the accident and emergency department with headache and left-sided vasomotor symptoms including reduced muscle tone, weakness and slurring of speech upon walking. Further discussion revealed that she had been suffering from similar symptoms of varying severity over the past year but that for 3 months the symptoms had been increasing in frequency and severity. She thought they were migraines and treated them unsuccessfully with paracetamol.

She had no significant previous medical history, was on no medication at the time of presentation and did not report any known allergies. Physical examination of the neurological system confirmed left hemiparesis with paresthesia and VIIth cranial nerve palsy with unilateral facial weakness and ptosis which rose initial suspicions of underlying vascular central nervous system (CNS) pathology. Abdominal examination revealed a heterogenous, hard and enlarged but painless liver. Observations included BP: $155 / 85 \mathrm{mmHg}$, HR: $115 \mathrm{bpm}, \mathrm{T}: 36.8^{\circ} \mathrm{C}$ and RR: $19 / \mathrm{min}$. There were no other significant findings on examination.

\section{Investigation}

Initial $A \& E$ assessment, revealed a low non-fasting venous glucose consentration of $1.7 \mathrm{mmol} / \mathrm{l}(30.1 \mathrm{mg} / \mathrm{dl})$ whilst further routine biochemistry markers were normal.

Previous blood glucose levels as performed by the patient's GP a few months earlier were unremarkable (FBG: $4.7 \mathrm{mmol} / \mathrm{l}$ - 09/2006). The patient was not overweight (BMI: $23 \mathrm{~kg} / \mathrm{m}^{2}$ ) There was no family history of impaired glucose control. The patient was admitted for symptom control and further diagnostics.

During her inpatient stay, she developed frequent hypoglycaemias especially at night that required treatment with i.v. administration of dextrose and/or glucagon. Further endocrine investigations (Table 1) for insulin, C-peptide and baseline cortisol $(532 \mathrm{mmol} / \mathrm{l})$ were requested and a Synacthen test was performed which

Table 1 Initial evaluation for sources of hypoglycemia.

\begin{tabular}{|c|c|c|}
\hline Investigations & $\begin{array}{l}\text { Patient's } \\
\text { serum }\end{array}$ & Reference range \\
\hline Glucose & $1.7 \mathrm{mmol} / \mathrm{l}$ & $4.0-5.9 \mathrm{mmol} / \mathrm{l}$ \\
\hline Insulin & $<10 \mathrm{pmol} / \mathrm{l}$ & $<174$ pmol/l (fasting) \\
\hline C-peptide & $99 \mathrm{pmol} / \mathrm{l}$ & $170-900 \mathrm{pmol} / \mathrm{l}$ (fasting) \\
\hline Cortisol & $532 \mathrm{mmol} / \mathrm{l}$ & $190-720 \mathrm{mmol} / \mathrm{l}(0900 \mathrm{~h})$ \\
\hline Chlorpropamide & $0 \mu \mathrm{g} / \mathrm{ml}$ & $0 \mu \mathrm{g} / \mathrm{ml}$ \\
\hline Tolazamide & $0 \mu \mathrm{g} / \mathrm{ml}$ & $0 \mu \mathrm{g} / \mathrm{ml}$ \\
\hline Tolbutamine & $0 \mu \mathrm{g} / \mathrm{ml}$ & $0 \mu \mathrm{g} / \mathrm{ml}$ \\
\hline Acetohexamide & $0 \mu \mathrm{g} / \mathrm{ml}$ & $0 \mu \mathrm{g} / \mathrm{ml}$ \\
\hline Glipizide & $0 \mu \mathrm{g} / \mathrm{ml}$ & $0 \mu \mathrm{g} / \mathrm{ml}$ \\
\hline Gliclazide & $0 \mu \mathrm{g} / \mathrm{ml}$ & $0 \mu \mathrm{g} / \mathrm{ml}$ \\
\hline IGF1 & $5.1 \mathrm{nmol} / \mathrm{l}$ & $6-36 \mathrm{nmol} / \mathrm{l}$ \\
\hline IGF2 & $96.5 \mathrm{nmol} / \mathrm{l}$ & \\
\hline IGF2/1 ratio & 18.9 & $<10$ \\
\hline Betahydroxybutyrate & $330 \mu \mathrm{mol} / \mathrm{l}$ & \\
\hline
\end{tabular}



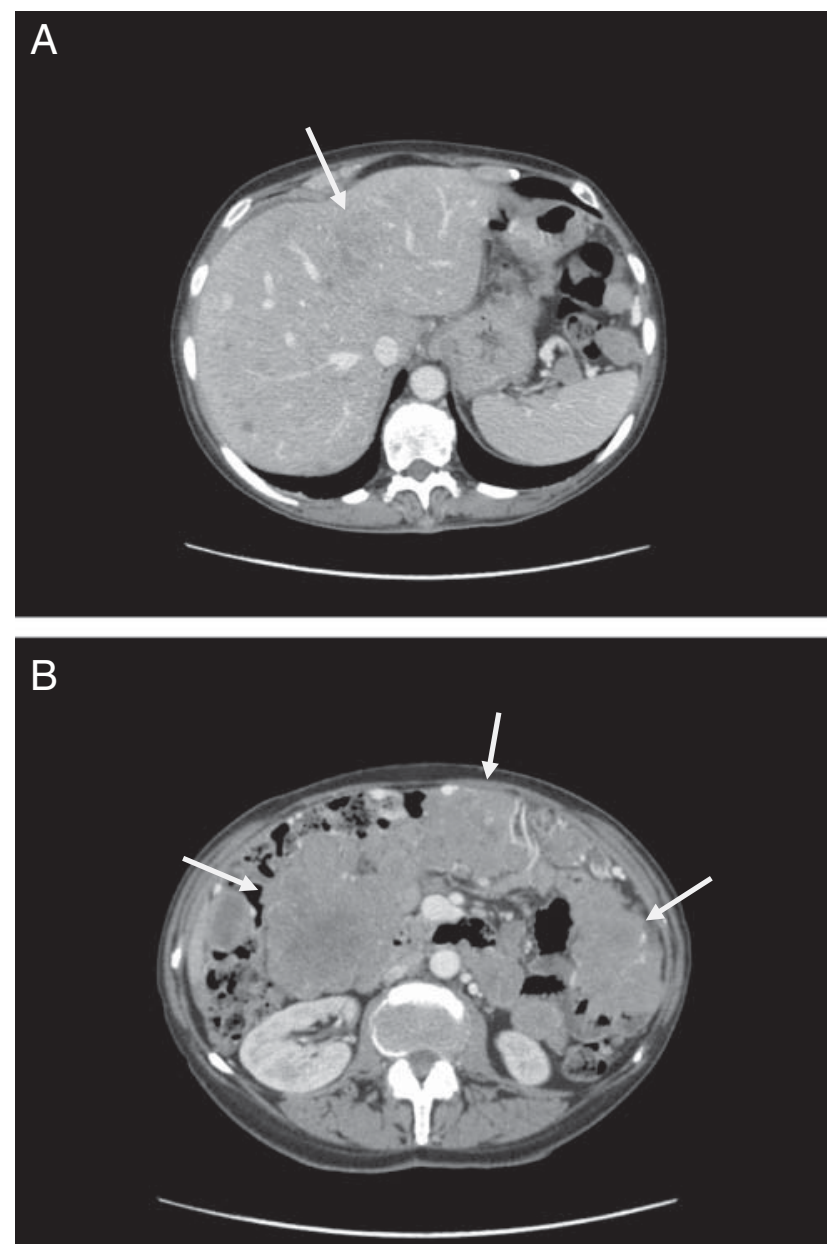

Figure 1

Dual phase, contrast enhanced abdominal (A) and liver (B) CT scans pre-imatinib mesylate treatment. Marked with arrows is the impressive long term disease response (27/07/2007)

excluded longer-term onset adrenal insufficiency (serum cort $\left.\left(0^{\prime}\right) 390 \mathrm{nmol} / 1,\left(30^{\prime}\right) 773 \mathrm{nmol} / \mathrm{l}\right)$.

A dual phase contrast enhanced CT scan revealed multiple lobulated masses in the abdomen and pelvis. The two largest lobulated masses were located in the pelvis, measuring $14 \times 8 \mathrm{~cm}$ in the axial plane, extending into the lower abdomen; and another in the suprapubic region measuring $9 \times 11 \mathrm{~cm}$. Each of these pelvic masses showed uneven enhancement, with areas of low density, either cystic or necrotic. There was another large, lobulated omental mass with similar characteristics, and multiple peritoneal and mesenteric masses of varying sizes. In addition, there were multiple poorly defined low density lesions scattered throughout the liver in keeping with secondary deposits (Fig. 1A and B).

An ultrasound guided biopsy of the largest pelvic mass $(14 \times 8 \mathrm{~cm})$ was performed. Histological analysis confirmed the diagnosis of a GIST, strongly positive for proto-oncogene c-KIT CD117 and CD34 (Fig. 2A and B). Disease extent based on TNM staging was pT4N1M1 G3 (Stage IV). Based on international and national guidelines
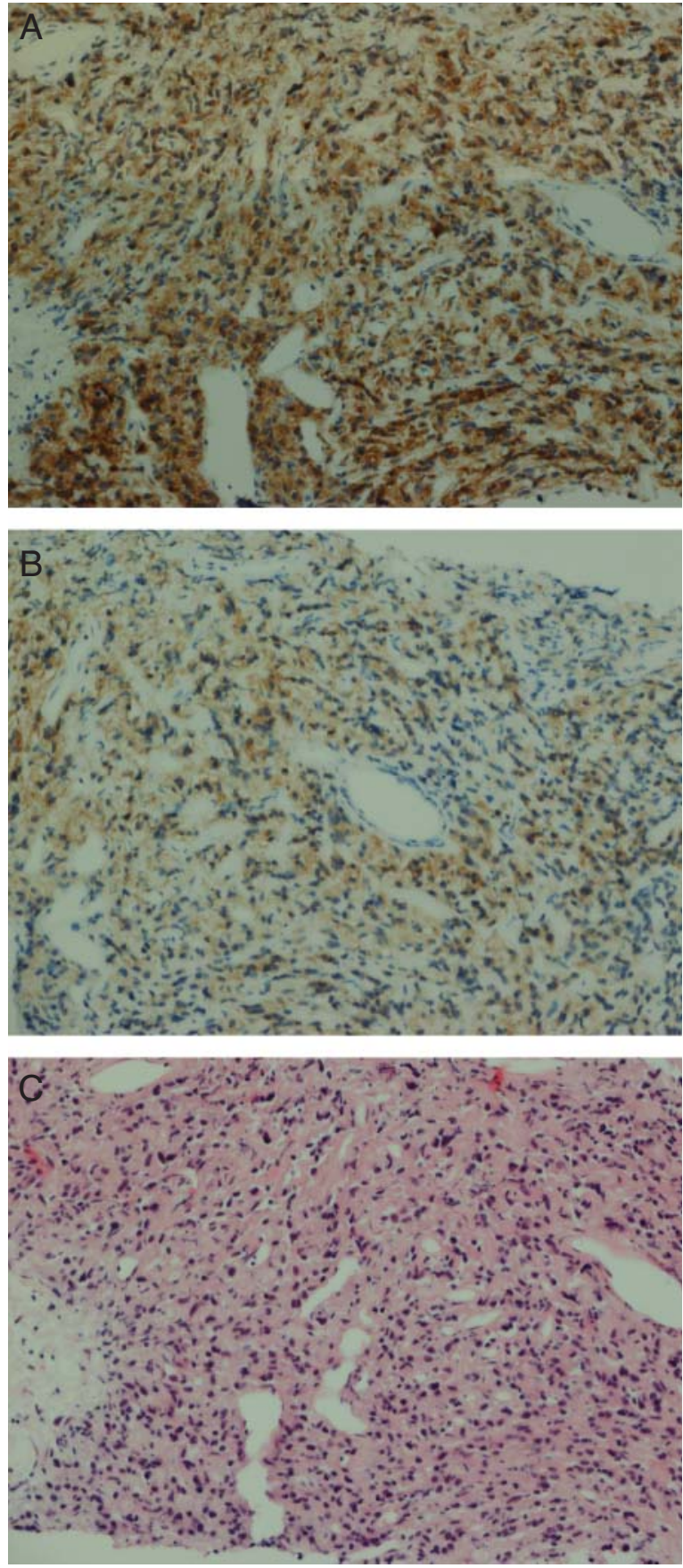

\section{Figure 2}

(A) and (B) Immunohistochemical study showing tumour cells positive for proto-oncogene c-kit (CD 117) and DOG-1. (C) Light microscopy showing hypercellular spindle cells arranged in fascicles and whorls. 
(2), tissue samples were sent for mutational analysis of KIT and PDGFR variations.

The diagnosis of an NICTH secondary to an IGF2 secreting GIST was further confirmed biochemically (IGF2 $96.5 \mathrm{nmol} / \mathrm{l}$; IGF2:IGF1 ratio 18.9 (reference ratio <10)). Insulin and C Peptide levels were invariably suppressed in correlation with the profound hypoglycaemia at the time of analysis.

\section{Treatment}

Prior to availability of the histopathology results, treatment with diazoxide ( $5 \mathrm{mg} / \mathrm{kg}$ per day given 8 hourly) was provided for 5 days but failed to control her hypoglycaemic episodes as can be anticipated in subsequently confirmed NICTH, given that NICTH related hypoglycemia is not responsive to K-ATP channel activity (3).

Prednisolone $20 \mathrm{mg}$ once daily in the morning was started 7 days after initial presentation and adequately controlled her symptoms allowing weaning from i.v. glucose (4) (5). To minimise steroid induced side effects, treatment with recombinant human growth hormone was added (4) (5) (6), which allowed tapering down the dose of prednisolone.

Further treatment options for GISTs include surgery or targeted cyto-reductive therapy with highly specific Imatinib mesylate, especially in the adjuvant setting and metastatic disease with focus on tumour burden reduction.

Mutational analyses indicated the presence of the common KIT exon 11 mutation. At this point, following MDT discussion targeted therapy with selective antiPDGFR $\alpha$ and anti-KIT tyrosine kinase inhibitor (TKI) Imatinib mesylate was deemed as the most suitable treatment option due to the extensive disease. Treatment with the lowest $400 \mathrm{mg} /$ day Imatinib mesylate dose was initiated based on the results of the mutational analysis and existing guidelines for the common KIT exon 11 mutation response to Imatinib mesylate.

\section{Outcome and follow-up}

Treatment with Imatinib mesylate caused rapid neuroglucopenic symptom control and allowed for further tapering of the steroid dose until discontinuation in August 2007. Therapy with human recombinant growth hormone was also discontinued as the patient stopped having hypoglycaemias within weeks after first receiving Imatinib mesylate.
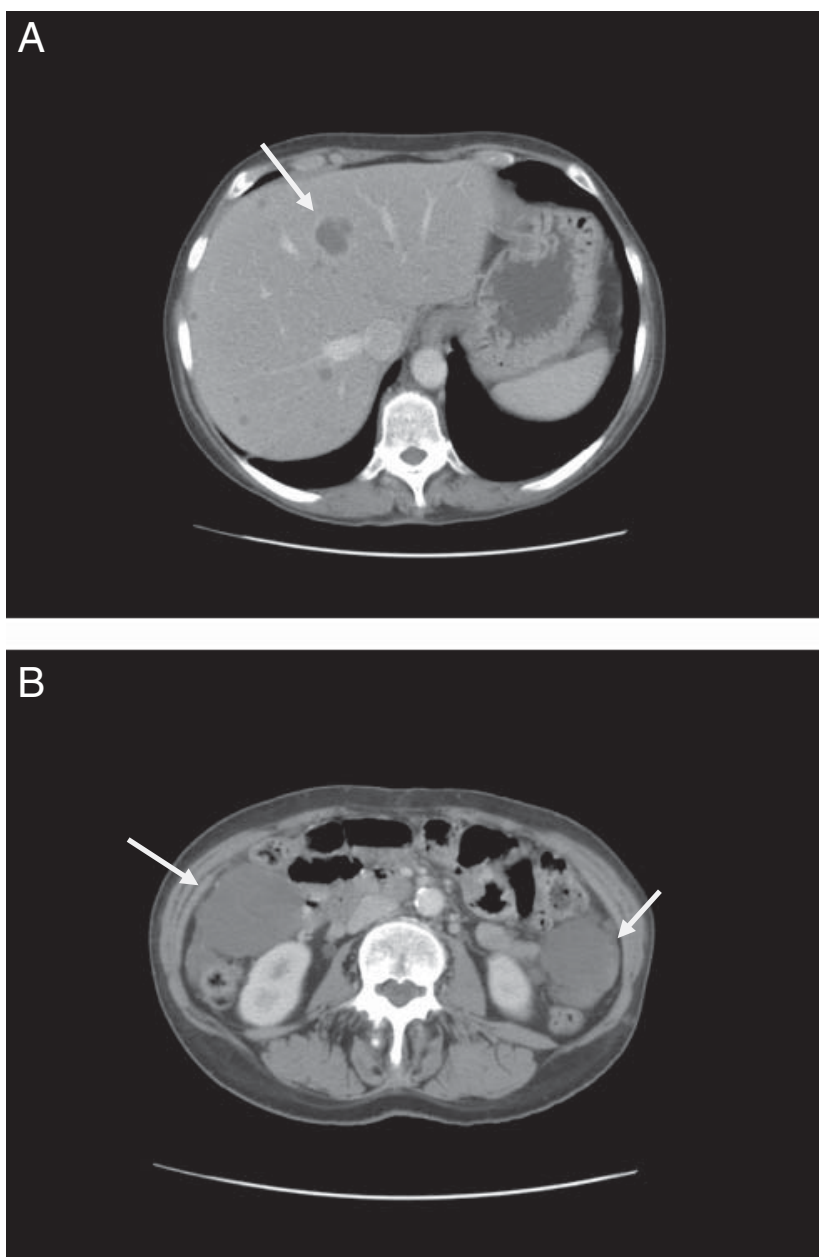

Figure 3

Dual phase, contrast enhanced abdominal (A) and liver (B) CT scans postimatinib mesylate treatment. Marked with arrows is the impressive long term disease response (15/02/2015).

Tumour burden was dramatically reduced and long term partial response was achieved ( $>30 \%$ tumour load shrinkage) without any signs of tumour dedifferentiation or development of gradual resistance to therapy even after 8 years following the diagnosis (Fig. 3A and B).

The patient today aged 78 years old still continues to do well on the preceding treatment and at present does not experience any hypoglycaemic episodes or related symptoms. Nevertheless, she still continues to monitor her glucose levels and has IM glucagon and support in the case of an emergency.

\section{Discussion}

The incidence of NICTH ranges from 2.1 to 15 per million people and is evenly distributed between genders (7) (8). 
NICTH typically occurs with large or metastatic usually parenchymal tumours, but may rarely also present in other types of cancer such as advanced adenocarcinomas of the colon (4) (9).

Searching PubMed for 'GIST' and 'hypoglycaemia' only reveals 10 previous reports. In four of the cases expression of 'big' IGF2 was reported and in two cases there was over expression of pro-IGF2 (10) (11). High concentrations of pre-pro-IGF2 genes that are not properly glycosylated result in the high molecular weight 'big' IGF2. Compared to physiologic IGF2, it has a significantly higher affinity to the insulin receptor, and a lower affinity to its binding protein (IGFBP-3) (1). The association of 'big' IGF2 and NICTH was first reported by Daughaday et al. in a patient with a fibrosarcoma (9). Non islet cell tumour-induced hypoglycemia secondary to 'big' IGF2 is difficult to confirm because routine diagnostic tests are not widely available.

Hence, an easier accessible pathognomic biochemical feature can be an IGF2:IGF1 ratio of $\geq 10$ as well as low insulin, c-peptide and growth hormone concentrations. However, the exact mechanisms of GIST induced hypoglycaemia are incompletely identified. Possible explanations include impaired glucose metabolism or decreased hepatic gluconeogenesis. In addition, given that clinically detectable hypoglycaemia appears to be associated with high tumour burden, auto-paracrine IGF2-mediated increased glucose metabolism may contribute in explaining hypoglycaemia in GISTs (12).

Optimal management of NICTH includes hypoglycaemia symptom control, surgical removal of the primary tumour if amenable to surgical resection, thereby targeting the source of IGF2 excess ectopic production. However, in extensively disseminated disease, as was the case of our patient, targeted medical treatment appears to be an effective alternative option for the treatment of GIST induced NICTH.

Mutational analysis in GIST is crucial as it identifies less sensitive or resistant genotypes (PDGFR D842V) who may not benefit from therapy with the selective TKI Imatinib mesylate and allows dose adjustment for patients with KIT exon 9 mutations $(800 \mathrm{mg} /$ day) whereas the standard dose in the most common KIT exon 11 mutation is $400 \mathrm{mg} /$ day.

For the treatment of severe hypoglycaemic episodes, various pharmacological treatments are available. Diazoxide is often tried but is usually ineffective as its effect is through normal K-ATP channels. Steroids and growth hormone represent an alternative palliative strategy for short-term management of symptomatic hypoglycaemia.
Treatment with Imatinib appears to be another effective option but is expensive and not always successful at managing symptoms of hypoglycaemia. Surgical resection remains the most rapid and cost-effective therapy to normalize glucose metabolism in most cases of NICTH and should be the preferable option when indicated.

\section{Declaration of interest}

The authors declare that there is no conflict of interest that could be perceived as prejudicing the impartiality of the research reported.

\section{Funding statement}

This research did not receive any specific grant from any funding agency in the public, commercial or not-for-profit sector.

\section{Patient consent}

We confirm that a written informed consent has been obtained from the patient for publication of the submitted article and accompanying images.

\section{Author contribution statement}

All co-authors listed contributed substantially to the preparation of this manuscript. Permission to publish this case was given by Dr N Murthy who was the attending physician of the patient.

\section{References}

1 Rikhof B, van Doorn J, Suurmeijer AJ, Rautenberg MW, Groenen PJ, Verdijk MA, Jager PL, de Jong S, Gietema JA \& van der Graaf WT 2009 Insulin-like growth factors and insulin-like growth factor-binding proteins in relation to disease status and incidence of hypoglycaemia in patients with a gastrointestinal stromal tumour. Annals of Oncology $\mathbf{2 0}$ 1582-1588. (doi:10.1093/annonc/mdp038)

2 ESMO Sarcoma \& GIST Guidelines. 2014 Annals of Oncology 25 (Supplement 3): iii21-iii26. (doi:10.1093/annonc/mdu255)

3 Hussain K, Cosgrove KE, Shepherd RM, Chapman JC, Swift SM, Smith VV, Kassem SA, Glaser B, Lindley KJ, Aynsley-Green A et al. 2002 Uncontrolled insulin secretion from a childhood pancreatic beta-cell adenoma is not due to the functional loss of ATP sensitive potassium channels. Endocrine-Related Cancer 9 221-226. (doi:10.1677/erc.0 0090221)

4 Teale JD \& Wark G 2004 The effectiveness of different treatment options for non-islet cell tumour hypoglycaemia. Clinical Endocrinology 60 457-460. (doi:10.1111/j.1365-2265.2004.01989.x)

5 LeRoith D 2004 Non-islet cell hypoglycemia. Annales d'Endocrinologie 65 99-103. (doi:10.1016/S0003-4266(04)95641-7)

6 Bourcigaux N, Arnault-Ouary G, Christol R, Perin L, Charbonnel B \& Le Bouc Y 2005 Treatment of hypoglycemia using combined glucocorticoid and recombinant human growth hormone in a patient with a metastatic non-islet cell tumor hypoglycemia. Clinical Therapeutics $\mathbf{2 7}$ 246-251. (doi:10.1016/j.clinthera.2005.02.004)

7 Escobar GA, Robinson WA, Nydam TL, Heiple DC, Weiss GJ, Buckley L, Gonzal R \& McCarter MD 2007 Severe paraneoplastic hypoglycaemia in a patient with a gastrointestinal stromal tumour with an exon 9 mutation: a case report. BMC Cancer 7 13. (doi:10.1186/14712407-7-13) 
Endocrinology,

Diabetes \& Metabolism

CASE REPORT
G K Dimitriadis and others

Paraneoplastaic hypoglycemia secondary to a GIST
8 Service FJ, McMahon MM, O’Brien PC \& Ballard DJ 1991 Functioning insulinoma-incidence, recurrence, and long-term survival of patients: a 60-year study. Mayo Clinic Proceedings 66 711-719. (doi:10.1016/S00256196(12)62083-7)

9 Daughaday WH 1989 Hypoglycemia in patients with non-islet cell tumors. Endocrinology and Metabolism Clinics of North America 18 91-101.

10 Beckers MM, Slee PH \& van Doorn J 2003 Hypoglycaemia in a patient with a gastrointestinal stromal tumour. Clinical Endocrinology 59 402-404. (doi:10.1046/j.1365-2265.2003.01848.x)
11 Hamberg P, de Jong FA, Boonstra JG, van Doorn J, Verweij J \& Sleijfer S 2006 Non-islet-cell tumor induced hypoglycemia in patients with advanced gastrointestinal stromal tumor possibly worsened by imatinib. Journal of Clinical Oncology 24 e30-e31. (doi:10.1200/ JCO.2006.06.5318)

12 Pink D, Schoeler D, Lindner T, Thuss-Patience PC, Kretzschmar A, Knipp H, Vanhoefer U \& Reichardt P 2005 Report of two cases severe hypoglycemia caused by paraneoplastic production of IGF-II in patients with advanced gastrointestinal stromal tumours. Journal of Clinical Oncology 23 6809-6811. (doi:10.1200/JCO.2005.02.4828)

Received in final form 10 September 2015

Accepted 21 September 2015 